\title{
Elevated plasma pentraxin-3 in polycystic ovary syndrome is associated with hyperandrogenism: a case-control study
}

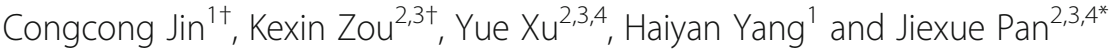

\begin{abstract}
Background: Pentraxin 3 (PTX3) - a crucial humoral innate immunity component - is related to obesity and cardiovascular complications in women who suffer from polycystic ovary syndrome (PCOS). However, the circulating PTX3 level in PCOS is still debated. In this study, we aimed to evaluate PTX3 plasma levels in PCOS women of childbearing age, and find possible endocrine/metabolic factors that could affect this level.

Methods: A total of 360 women were enrolled: 120 PCOS women and 240 body mass index (BMI) matched normally ovulating women. Blood samples were collected on the third day of natural menstrual cycle or from the bleeding after progesterone withdrawal. The PTX3 concentration was measured by immunoassay.

Results: The PTX3 plasma level was significantly higher in PCOS women compared to controls. There was a positive correlation between PTX3 plasma level and PCOS diagnosis, overweight, cycle length, serum LH to FSH ratio, estradiol, total testosterone (TT) on the third day of menstrual cycle, antral follicle count (AFC), as well as uric acid. Multivariant linear regression analysis indicated that participants' serum PTX3 levels were proportional to the circulating $T$ level, existence of PCOS, basal estradiol level and AFC.

Conclusions: Overall, the circulating PTX3 level was elevated in PCOS women and significantly associated with the presence of hyperandrogenism. This study provided the basis for further in-depth researches regarding PTX3 role in PCOS pathophysiology.
\end{abstract}

Keywords: Polycystic ovary syndrome, PTX3, Hyperandrogenism, Innate immunology

\section{Introduction}

Polycystic ovary syndrome (PCOS) has multiple symptoms and is one of the most common endocrine disorders affecting women of child-bearing age [1]. Its prevalence worldwide varies from 5 to $19.9 \%$ [2-4]. This syndrome is associated with hyperandrogenism, ovulatory dysfunction, decreased infertility, psychological discomfort [5] and

\footnotetext{
* Correspondence: panjiexue@fudan.edu.cn

${ }^{+}$Congcong Jin and Kexin Zou contributed equally to the present work.

${ }^{2}$ Obstetrics \& Gynecology Hospital, Institute of Reproduction and Development, Fudan University, 200011 Shanghai, China

${ }^{3}$ Shanghai Key Laboratory of Embryo Original Diseases, 200030 Shanghai, China

Full list of author information is available at the end of the article
}

increased incidence of metabolic abnormalities, such as insulin resistance and cardiovascular diseases [1]. Also, PCOS is a common cause of infertility, pregnancy complications, and unfavorable neonatal outcomes [6]. The heterogeneity of the condition leads to difficulties in etiology identification, and although several clinical trials and investigations have been conducted to comprehend its pathophysiological mechanisms [7], the details underpinning PCOS remain insufficiently understood.

Evidence supporting that PCOS is associated with chronic inflammatory state is emerging [8]. PCOS is associated with pro-inflammatory cytokines and chemokines elevation in plasma, such as interleukin-18 (IL-18)

(c) The Author(s). 2021 Open Access This article is licensed under a Creative Commons Attribution 4.0 International License, which permits use, sharing, adaptation, distribution and reproduction in any medium or format, as long as you give appropriate credit to the original author(s) and the source, provide a link to the Creative Commons licence, and indicate if changes were made. The images or other third party material in this article are included in the article's Creative Commons licence, unless indicated otherwise in a credit line to the material. If material is not included in the article's Creative Commons licence and your intended use is not permitted by statutory regulation or exceeds the permitted use, you will need to obtain permission directly from the copyright holder. To view a copy of this licence, visit http://creativecommons.org/licenses/by/4.0/ The Creative Commons Public Domain Dedication waiver (http://creativecommons.org/publicdomain/zero/1.0/) applies to the data made available in this article, unless otherwise stated in a credit line to the data. 
[9], monocyte chemoattractant protein-1 (MCP-1) [10, 11], and chemokine (C-C motif) ligand 3 (CCL3) [10]. Additionally, researchers have found an increased $\mathrm{CD} 19^{+} \mathrm{B}$ cells proportion and activity in PCOS women [12], which indicates a pathogenic role of lymphocytes in the development of the disease.

Innate immunity includes two facets: cellular and humoral. Pentraxin 3 (PTX3) is a fluid-phase pattern recognition molecule that belongs to the acute-reactants superfamily [e.g. C-reactive protein (CRP)]. It has many properties and can bind different molecules. Particularly, PTX3 is important for selected pathogens opsonization [13] and female fertility [14, 15]. Unlike the short pentraxin, PTX3 can be locally produced in response to inflammation by different cell types, including adipocytes [16], endothelial cells [17] and follicle cells [7]. Our previous study indicated that follicular cells from PCOS women have higher PTX3 expression [7]. Also, PCOS women with healthy weight presented higher ovarian PTX3 levels [18]. PTX3 is essential for the organization of cumulus oophorus extracellular matrix and fertilization $[19,20]$. In mice, Ptx3 gene deletion leads to female infertility and cumulus matrix instability [21]. PTX3 can also participate in PCOS occurrence [22-25] and its related metabolic complications [26]. However, PTX3 role in PCOS is still under dispute. We hypothesized that PTX3 level is altered in PCOS women. In the present study, we aimed to assess if plasma PTX3 level is associated with PCOS and investigate clinical and hormonal factors that would affect this level.

\section{Materials and methods}

\section{Patient selection and sample collection}

This case-control study was performed following the Declaration of Helsinki and approved by the Institutional Review Board of the First Affiliated Hospital of Wenzhou Medical University. Recently diagnosed PCOS (120) and normally ovulating women (240) were enrolled during January 2017 to August 2018 and gave written consent. All the subjects were referred to our reproductive department for infertility or pre-pregnancy checkup. PCOS patients were diagnosed according to the Rotterdam Consensus (European Society for Human Reproduction and Embryology/American Society for Reproductive Medicine criteria) [2]. All the PCOS cases in the present study had the ovulating dysfunction plus polycystic ovarian morphology after exclusion of specific identifiable disorders (adrenal hyperplasia, androgen-secreting tumors, hyperprolactinemia and Cushing's syndrome). Additionally, each control woman met the following inclusion criteria: (1) normal ovarian volume; (2) menstrual cycle length between 26 and 33 days; (3) clinical, biochemical and sex hormonal profiles were within normal ranges; (4) no polycystic ovary morphology. All subjects in our study met the following inclusion criteria: (1) age between 21 and 35; (2) both ovaries present; (3) nonsmokers, normotensive, and not a regular consumer of alcoholic beverages; (4) did not have malign diseases, pelvic infections, chronic systemic diseases, and endometriosis diagnosed by vaginal ultrasound and/or laparoscopy; (5) none of the cases or controls was on any medications for at least 3 months prior the enrollment, including oral contraceptives, glucocorticoids, lipid-lowering, antiobesity, antidiabetes, antiandrogenic, and/-or ovulation-inducing agents.

For each PCOS woman, two normally ovulating women with matched body mass index (BMI) were recruited as the control group (240) to minimize the effect of metabolic disturbances. The BMI was calculated as body-weight divided by the squared height $\left(\mathrm{kg} / \mathrm{m}^{2}\right)$. Finally, subjects were separated into different groups (Tables 1 and 2; Fig. 1B) according to their BMI. In general, Chinese females have a lower BMI and percentage of body fat than do white ones [27], so the BMI cut-off points for overweight/obesity are $23 \mathrm{~kg} / \mathrm{m}^{2}$.

All subjects in our study met the following inclusion criteria: (1) age between 21 and 35; (2) both ovaries present; (3) nonsmokers, normotensive, and not a regular consumer of alcoholic beverages; (4) did not have malign diseases, pelvic infections, chronic systemic diseases, and endometriosis diagnosed by vaginal ultrasound and/or laparoscopy; (5) none of the cases or controls was on any medications for at least 3 months prior the enrollment, including oral contraceptives, glucocorticoids, lipid-lowering, antiobesity, antidiabetes, antiandrogenic, and/-or ovulation-inducing agents. Additionally, each control woman met the following inclusion criteria: (1) normal ovarian volume; (2) menstrual cycle length between 26 and 33 days; (3) clinical, biochemical and hormonal profiles were within normal ranges; (4) no polycystic ovary morphology.

All blood samples were collected on the third day of their natural menstrual cycle or from the bleeding after progesterone withdrawal. Five $\mathrm{mL}$ of venous blood were withdrawn in the morning between 8:00 and 9:00, after an overnight fast. Then, samples were centrifuged and the supernatants were stored at $-80{ }^{\circ} \mathrm{C}$ until further analysis.

\section{Laboratory parameters determination}

All blood samples were collected on the third day of their natural menstrual cycle or from the bleeding after progesterone withdrawal. Five $\mathrm{mL}$ of venous blood were withdrawn in the morning between 8:00 and 9:00, after an overnight fast. Then, samples were centrifuged and the supernatants were stored at $-80{ }^{\circ} \mathrm{C}$ until further analysis.

Blood tests including hormones and liver functions were performed at the clinical laboratory of the First Affiliated Hospital of Wenzhou Medical University. The levels of Day 3 serum hormones were quantified using 
Table 1 Demographic data and clinical characteristics of enrolled subjects

\begin{tabular}{|c|c|c|c|}
\hline Items & Control $(n=240)$ & PCOS $(n=120)$ & $P$ value \\
\hline Age (years) & $29.57 \pm 0.20$ & $28.33 \pm 0.27$ & $<0.001$ \\
\hline Body Mass Index $\left(\mathrm{kg} / \mathrm{m}^{2}\right)$ & $22.38 \pm 0.22$ & $22.54 \pm 0.30$ & 0.658 \\
\hline $\mathrm{BMI}<18.5(\mathrm{n}[\%])$ & 28 [11.67\%] & 14 [11.67\%] & \\
\hline $18.5 \leq \mathrm{BMI}<23(\mathrm{n}[\%])$ & 112 [46.67\%] & 56 [46.67\%] & \\
\hline $23 \leq \mathrm{BMI}<30(\mathrm{n}[\%])$ & $96[40 \%]$ & 48 [40\%] & \\
\hline $\mathrm{BMI} \geq 30(\mathrm{n}[\%])$ & 4 [1.67\%] & 2 [1.67\%] & \\
\hline Cycle length (days) & $30.56 \pm 0.17$ & $73.21 \pm 2.65$ & $<0.001$ \\
\hline Day 3 LH/FSH & $0.69 \pm 0.02$ & $1.34 \pm 0.07$ & $<0.001$ \\
\hline Day $3 \pi(\mathrm{nmol} / \mathrm{L})$ & $1.28 \pm 0.03$ & $1.71 \pm 0.05$ & $<0.001$ \\
\hline Day 3 PRL (mIU/L) & $315.75 \pm 8.11$ & $295.20 \pm 10.29$ & 0.131 \\
\hline Day $3 \mathrm{E}_{2}(\mathrm{pmol} / \mathrm{L})$ & $104.08 \pm 3.04$ & $157.63 \pm 4.90$ & $<0.001$ \\
\hline Antral follicle count & $12.75 \pm 0.34$ & $28.99 \pm 0.53$ & $<0.001$ \\
\hline Fasting glucose (mmol/L) & $5.26 \pm 0.03$ & $5.26 \pm 0.05$ & 0.906 \\
\hline Uric acid (umol/L) & $277.18 \pm 3.50$ & $316.14 \pm 6.69$ & $<0.001$ \\
\hline Creatinine (umol/L) & $50.27 \pm 0.48$ & $49.65 \pm 0.75$ & 0.474 \\
\hline Blood urea nitrogen (mmol/L) & $4.09 \pm 0.07$ & $4.18 \pm 0.09$ & 0.416 \\
\hline Bun/creatinine ratio & $20.48 \pm 0.36$ & $21.14 \pm 0.49$ & 0.289 \\
\hline ESR & $14.88 \pm 0.70$ & $16.34 \pm 0.99$ & 0.228 \\
\hline AST (U/L) & $18.51 \pm 0.37$ & $20.13 \pm 0.76$ & 0.031 \\
\hline $\operatorname{ALT}(U / L)$ & $14.58 \pm 0.54$ & $19.73 \pm 1.29$ & $<0.001$ \\
\hline Total cholesterol (mmol/L) & $4.50 \pm 0.05$ & $4.64 \pm 0.08$ & 0.106 \\
\hline Triglyceride (mmol/L) & $1.01 \pm 0.03$ & $1.42 \pm 0.08$ & $<0.001$ \\
\hline High-density lipoprotein (mmol/L) & $1.46 \pm 0.18$ & $1.37 \pm 0.32$ & 0.004 \\
\hline Low-density lipoprotein (mmol/L) & $2.49 \pm 0.04$ & $2.63 \pm 0.06$ & 0.04 \\
\hline Thyroid stimulating hormone (mIU/L) & $2.32 \pm 0.08$ & $2.35 \pm 0.11$ & 0.843 \\
\hline Free thyroxine (pmol/L) & $10.91 \pm 0.08$ & $11.35 \pm 0.14$ & 0.032 \\
\hline Free triiodothyronine (pmol/L) & $4.63 \pm 0.04$ & $4.77 \pm 0.06$ & 0.004 \\
\hline PTX3 (ng/ml) & $1.82 \pm 0.05$ & $2.46 \pm 0.07$ & $<0.001$ \\
\hline
\end{tabular}

Note: Day 3, the third day of spontaneous menstrual cycle; LH, luteinizinghormone; FSH, follicle stimulating hormone; $\Pi$, total testosterone; PRL, prolactin; E2, estradiol; ESR, erythrocyte sedimentation rate; ALT, alanine aminotransferase; AST, aspartate aminotransferase; PTX3, pentraxin 3

Values are presented as mean \pm SE. Significance was determined by Student $t$ tests

chemiluminescence assay (Unicel Dxl800, Beckman Coulter, USA). Fasting plasma glucose, serum triglycerides (TG), total cholesterol (TC), low-density lipoprotein (LDL), high-density lipoprotein (HDL) and hepatorenal function were measured by an autoanalyzer (AU5800, Beckman, USA). The plasma PTX3 levels were measured by The Quantikine Human Pentraxin 3/TSG-14 Immunoassay ( $R \& D$ Systems, Inc. Minneapolis, MN, USA) at the same time, and using reagents from the same lot to reduce measurement variability.

\section{Statistical analysis}

All statistical analyses were performed using the software SPSS version 24.0 (IBM Corp., Armonk, NY, USA). Continuous variables were noted as mean \pm SE. For data comparison between groups with and without PCOS, an independent student's t-test was used. The Pearson's correlation coefficient was used to measure associations between plasma PTX3 and other variables. A multivariate analysis was performed using backward stepwise linearlogistic regression. All tests were two-sided and $P$ values of 0.05 were considered statistically significant.

\section{Results}

Subjects' baseline characteristics demographic data and clinical features

The characteristics of PCOS and control subjects are presented in Table 1. We compared the anthropometric and biochemical parameters between groups, and due to the matching criteria employed in this study, there was no significant BMI difference (Table 1). Among subjects, PCOS women were younger and characterized by 
Table 2 Correlations of plasma PTX3 with each parameter

\begin{tabular}{|c|c|c|}
\hline Items & $R$ & $P$ value \\
\hline Existence of PCOS & 0.363 & $<0.001$ \\
\hline Age & -0.060 & 0.256 \\
\hline $\mathrm{BMI}>23$ & 0.171 & 0.001 \\
\hline Cycle length (days) & 0.236 & $<0.001$ \\
\hline Day 3 LH/FSH & 0.269 & $<0.001$ \\
\hline Day $3 \pi$ & 0.524 & $<0.001$ \\
\hline Day 3 PRL & 0.038 & 0.468 \\
\hline Day $3 \mathrm{E}_{2}$ & 0.306 & $<0.001$ \\
\hline Antral follicle count & 0.244 & $<0.001$ \\
\hline Fasting glucose (mmol/L) & -0.012 & 0.814 \\
\hline Uric acid (umol/L) & 0.189 & $<0.001$ \\
\hline Creatinine (umol/L) & 0.054 & 0.309 \\
\hline Blood urea nitrogen (mmol/L) & -0.015 & 0.783 \\
\hline Bun/creatinine ratio & -0.049 & 0.356 \\
\hline ESR & 0.035 & 0.506 \\
\hline AST (U/L) & 0.095 & 0.072 \\
\hline $\mathrm{ALT}(\mathrm{U} / \mathrm{L})$ & 0.075 & 0.155 \\
\hline Total cholesterol (mmol/L) & -0.007 & 0.889 \\
\hline Triglyceride (mmol/L) & 0.090 & 0.088 \\
\hline High-density lipoprotein (mmol/L) & -0.060 & 0.253 \\
\hline Low-density lipoprotein (mmol/L) & -0.009 & 0.865 \\
\hline Thyroid stimulating hormone (mIU/L) & -0.001 & 0.985 \\
\hline Free thyroxine (pmol/L) & 0.014 & 0.792 \\
\hline Free triiodothyronine $(\mathrm{pmol} / \mathrm{L})$ & 0.001 & 0.985 \\
\hline
\end{tabular}

Data are presented as Pearson correlation coefficients significantly $(P<0.05)$ longer menstrual cycle, higher antral follicle count (AFC), serum luteinizing hormone (LH)/follicle-stimulating hormone (FSH) ratio, total testosterone (TT), and estradiol $\left(\mathrm{E}_{2}\right)$ levels on the third day of menstrual cycle. Furthermore, compared with normally ovulating women, PCOS women had higher levels of uric acid, alanine aminotransferase (ALT), aspartate aminotransferase (AST), triglyceride, LDL, free thyroxine and free triiodothyronine, but lower HDL in the plasma. Among all subjects, 150 women were overweight/obese.

\section{Circulating PTX3 levels in PCOS women and controls}

The circulating PTX3 level was significantly higher in PCOS $(2.46 \pm 0.07 \mathrm{ng} / \mathrm{mL})$ than in control women $(1.82$ $\pm 0.05 \mathrm{ng} / \mathrm{mL}$ ) (Table 1; Fig. $1 \mathrm{~A}$ ), consisting in a marked elevation $(30 \%)(P<0.001)$. BMI group analyses revealed that the mean PTX3 concentrations were higher in lean and overweight/obese PCOS women than the normally ovulating groups (Fig. 1B), especially the lean subjects whose BMI was $<23$.

\section{Associations of enrolled parameters with circulating PTX3 levels}

Pearson's correlations were calculated to define parameters associated with plasma PTX3 levels (Table 2). Among all subjects, circulating PTX3 level had a positive relation with the existence of PCOS $(R=0.363, P<$ $0.001)$, overweight/obesity $(R=0.171, P=0.001)$, menstrual cycle length $(R=0.236, P<0.001)$, basal LH to FSH ratio $(R=0.269, P<0.001)$, TT $(R=0.524, P<$ $0.001)$, and serum $\mathrm{E}_{2}(R=0.306, P<0.001)$, as well as AFC $(R=0.244, P<0.001)$. Moreover, there was a positive correlation between plasma PTX3 level and uric acid $(R=0.189, P<0.001)$. However, no associations were observed between the plasma PTX3 level and age, basal serum PRL and the remaining metabolic parameters.
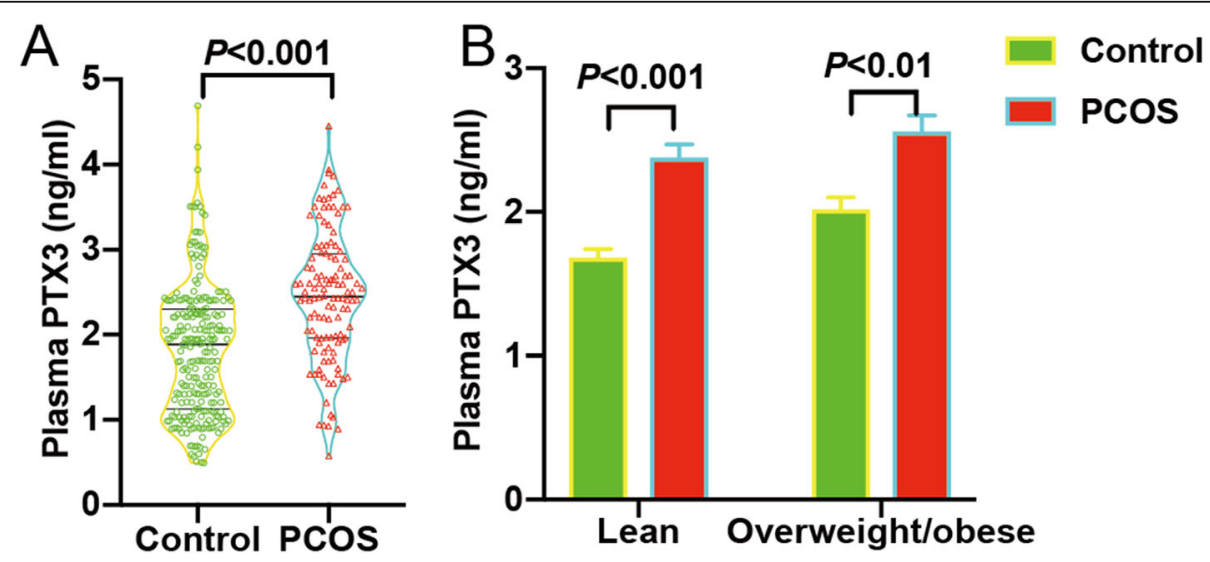

Fig. 1 A Plasma PTX3 levels among normal ovulating women and PCOS subjects. The bottom and top of each box indicate the 25th and 75th percentiles, respectively. The line through the middle of each box represents the median. B Plasma PTX3 level in BMI-stratified women. P value was determined by an unpaired t-test 
The multiple linear logistic regression analyses were employed to explore the possible effects of variables on the circulatory PTX3 level (Table 3). After adjustment for basal LH/FSH, cycle length and uric acid, the plasma PTX3 level was significantly associated with basal TT $(95 \% \mathrm{CI}=0.493 \sim 0.785)$ and the existence of PCOS (95\% CI $=0.228 \sim 0.776)$. Additionally, basal $\mathrm{E}_{2}(95 \% \mathrm{CI}$ $=0.000 \sim 0.030)$ and $\mathrm{AFC}(95 \% \mathrm{CI}=-0.027 \sim-0.001)$ showed weekly predictable values for plasma PTX3.

\section{Discussion}

Our study aimed to compare circulating PTX3 levels between BMI-matched PCOS and normally ovulating women. We observed a significant increase in plasma PTX3 levels of PCOS women. Meanwhile, TT level and the existence of PCOS were strongly associated with increased plasma PTX3.

PTX3 is an essential innate immunity component and increases in response to stress or inflammation. Based on its quaternary structure, PTX3 interacts with a series of ligands, playing multiple roles in different settings, such as cardiovascular diseases [28], fertility [14] and cancer [29]. In some inflammatory conditions, PTX3 has also been regarded as a biomarker for disease severity. Although both CRP and PTX3 are acute-phase proteins belonging to the pentraxin superfamily, the correlation between CRP and PTX3 levels was weak or absent in some conditions [30]. Unlike CRP, which is predominantly produced in the liver, PTX3 is synthesized in response to local inflammatory stimuli by a variety of cells including follicle cells [7, 18]. Several studies focusing on the chronic low-inflammatory state of PCOS indicated elevated CRP levels in this condition [31], and there were also several studies exploring the role of PTX3 in PCOS. However, the association between PTX3 and PCOS is still debated. The follicular PTX3 level among non-obese women was significantly higher in PCOS subjects and associated with the existence of PCOS and ovarian hyperandrogenism [18]. However, circulating PTX3 in PCOS women was previously reported as elevated [22, 23], diminished [24, 25], or similar [32] to non-PCOS subjects. Recently, researchers from Helsinki found that circulating PTX3 levels during in vitro fertilization could provide benefits in risk assessment for ovarian hyperstimulation syndrome [33]. Though the authors did not consider the existence of PCOS on the elevated PTX3 level, PCOS women are more predisposed to developing OHSS during the in vitro fertilization (IVF). This may provide explanation as the higher circulating PTX3 levels in our study. Katarzyna et al. have identified PTX3 as an endothelial dysfunction marker in young PCOS women [26]. Tosi et al. found that plasma PTX3 was decreased in PCOS women [24], but the enrolled PCOS subjects had significantly higher BMI (median $\mathrm{BMI}=28.5$ ) than non-PCOS ones (median BMI = 21.0). The differential BMI could be the possible explanations for the disaccord with our study. The correlations between PTX3 and BMI have been discussed in several studies, but there is no conclusive result $[22,25]$. Therefore, it is of great significance to evaluate the plasma PTX3 level between BMI-matched PCOS and non-PCOS women. In our current study, the PCOS group and the controls were BMI-matched to minimize the effect of fat mass percentage and related metabolic disturbances on plasma PTX3 level. The average PTX3 level was $1.82 \pm 0.05 \mathrm{ng} / \mathrm{mL}$ in normally ovulating women, whereas in PCOS women it was $2.46 \pm 0.07 \mathrm{ng} /$ $\mathrm{mL}$. The association analysis (Table 2) revealed a positive association between obese/overweight status and plasma PTX3. However, the association attenuated after multivariant regression analysis was introduced. This could be due to the fact that the majority of subjects in our study were lean.

Although we have matched the BMI levels, there were significant differences in several metabolic parameters between the two groups (Table 1). However, we did not

Table 3 Stepwise multiple regression analyses between plasma PTX3 and variables associated PTX3 in linear regression analysis

\begin{tabular}{|c|c|c|c|c|c|}
\hline \multirow[t]{2}{*}{ Variable } & \multicolumn{2}{|c|}{ Unstandardized coefficients } & \multirow{2}{*}{$\begin{array}{l}\text { Standardized coefficients } \\
\text { Beta }\end{array}$} & \multirow[t]{2}{*}{$P$ value } & \multirow{2}{*}{$\begin{array}{l}(95 \% C l) \\
\text { for } B\end{array}$} \\
\hline & B & Std. Error & & & \\
\hline Constant & 0.959 & 0.146 & & $<0.001$ & $(0.671 \sim 1.247)$ \\
\hline Day $3 \pi$ & 0.639 & 0.074 & 0.416 & $<0.001$ & $(0.493 \sim 0.785)$ \\
\hline Existence of PCOS & 0.502 & 0.139 & 0.288 & 0.001 & $(0.228 \sim 0.776)$ \\
\hline Overweight/obese or not & 0.137 & 0.074 & 0.082 & 0.065 & $(-0.009 \sim 0.283)$ \\
\hline Day $3 \mathrm{E}_{2}$ & 0.002 & 0.001 & 0.108 & 0.030 & $(0.000 \sim 0.003)$ \\
\hline AFC & -0.014 & 0.007 & -0.159 & 0.036 & $(-0.027 \sim-0.001)$ \\
\hline Adjusted $R^{2}$ & 0.322 & & & & \\
\hline$P$ value of the model & $<0.001$ & & & & \\
\hline Std error of the estimate & 0.677 & & & & \\
\hline
\end{tabular}

These factors were adjutsted in the multivariate regression analysis: BMI, Day 3 LH/FSH, cycle length and uric acid 
find any correlation between plasma PTX3 and these parameters, except for uric acid. Multiple regression analyses revealed that only circulating androgen level and the existence of PCOS were significantly correlated with could be the main predicable variables for plasma PTX3.

Most PCOS women suffer from hyperandrogenism [7, 34], and the PCOS women in this study also showed higher serum TT levels. There is evidence of a suppressive role of androgen on immune reactions [35], and the higher autoimmune diseases prevalence in women also indicates its immunosuppressive effect [36]. While Wang et al. suggested that exposure to hyperandrogenism might stimulate chronic ovarian inflammation [37], and Ashcroft et al. reported an immuno-enhancing effect of testosterone on macrophages [38]. Additionally, in vivo and in vitro studies also suggested that androgen excess stimulates inflammatory response in PCOS women [39]. Despite androgen being an immunoregulator, the potential role of hyperandrogenism on women's the immune response, especially innate immunity has never been fully illustrated. PTX3 is synthesized by different cells including adipocytes [16], endothelial cells [17] and follicle cells [7], and is involved in PCOS metabolic complications. Previous study has found that PCOS women had higher PTX3 expression in follicle cells [7], and aberrant DNA modification and hyperandrogenism might be possible pathogenies. The results in this study also indicate that hyperandrogenism might induce PTX3 overproduction. However, whether elevated circulting PTX3 is an indicator of the severity of innate immunity or is a compensatory mechanism of hyperandrogenism, and the mechanisms related androgen-induced higher PTX3 expression requires further study.

The present study also has limitations. First, although we have matched the two groups with BMI, most women from China are relatively thin and most subjects enrolled in our study were non-obese, even the PCOS ones. And most PCOS women suffered from insulin resistance. It is of significance to confirm our results in more subjects, obese and non-obese; and insulin resistance should also be measured. Second, we measured the PTX3 level only during follicular phase and further studies should consider PTX3 variations during different menstrual stages. Finally, all the enrolled subjects were relatively young.

\section{Conclusions}

We found that PCOS women had markedly increased PTX3 levels. Also, hyperandrogenism and the existence of PCOS were valuable predictors for elevated PTX3. This suggested that androgen may be a mediator in the pathogenesis of chronic low-grade inflammation for PCOS women.

\section{Acknowledgements}

The authors would like to thank the laboratory staff for the support in maintaining and analyzing the samples and they are also grateful to all women who participated in this study.

\section{Authors' contributions}

C. J., K. Z. and J. P. contributed to design of the study and drafted the manuscript; K. Z. and J. P. did the experiment and were involved in the acquisition of data. C. J., Y. X., H. Y. and J. P. collected the sample and revised the article. The author(s) read and approved the final manuscript.

\section{Funding}

This study was supported by Natural Science Foundation of China (No. 82171688, 81801411); Zhejiang Provincial Natural Science Foundation of China (No. LQ18H040005); Shanghai Pujiang Program (2020PJD077); China Scholarship Council scholarship (No. 201808330159); and Shanghai Municipal Health Commission (No. 2020Y0234).

\section{Availability of data and materials}

The datasets used or analysed during the current study are available from the corresponding author on reasonable request.

\section{Declarations}

Ethics approval and consent to participate

This study was approved by the Institutional Review Board of the First Affiliated Hospital of Wenzhou Medical University. All the enrolled subjects gave a written consent.

\section{Consent for publication}

Written informed consent for publication was obtained from all participants.

\section{Competing interests}

The authors declare that they have no competing interests.

\section{Author details}

${ }^{1}$ The First Affiliated Hospital of Wenzhou Medical University, 325000 Wenzhou, China. ${ }^{2}$ Obstetrics \& Gynecology Hospital, Institute of Reproduction and Development, Fudan University, 200011 Shanghai, China. ${ }^{3}$ Shanghai Key Laboratory of Embryo Original Diseases, 200030 Shanghai, China. ${ }^{4}$ Shanghai Ji Ai Genetics and IVF Institute, Obstetrics and Gynecology Hospital, Fudan University, 200011 Shanghai, China.

Received: 27 May 2021 Accepted: 25 October 2021

Published online: 03 December 2021

\section{References}

1. Hoeger K, Dokras A, Piltonen T. Update on PCOS: Consequences, Challenges and Guiding Treatment. The Journal of Clinical Endocrinology \& Metabolism. 2020;106(3):e1071-e83.

2. group TREA-sPcw. Revised 2003 consensus on diagnostic criteria and longterm health risks related to polycystic ovary syndrome (PCOS). Human reproduction (Oxford, England). 2004;19(1):41-7.

3. Azziz R. PCOS in 2015: New insights into the genetics of polycystic ovary syndrome. Nat Rev Endocrinol. 2016;12(2):74-5.

4. Azziz R, Kintziger K, Li R, Laven J, Morin-Papunen L, Merkin S, et al. Recommendations for epidemiologic and phenotypic research in polycystic ovary syndrome: an androgen excess and PCOS society resource. Human reproduction. 2019;34(11):2254-65.

5. Moran L, Deeks A, Gibson-Helm M, Teede H. Psychological parameters in the reproductive phenotypes of polycystic ovary syndrome. Human reproduction. 2012;27(7):2082-8.

6. Mills G, Badeghiesh A, Suarthana E, Baghlaf H, Dahan M. Associations between polycystic ovary syndrome and adverse obstetric and neonatal outcomes: a population study of 9.1 million births. Human reproduction. 2020;35(8):1914-21.

7. Pan J-X, Tan Y-J, Wang F-F, Hou N-N, Xiang Y-Q, Zhang J-Y, et al. Aberrant expression and DNA methylation of lipid metabolism genes in PCOS: a new insight into its pathogenesis. Clinical Epigenetics. 2018;10(1):6.

8. Rostamtabar M, Esmaeilzadeh S, Tourani M, Rahmani A, Baee M, Shirafkan F, et al. Pathophysiological roles of chronic low-grade inflammation mediators 
in polycystic ovary syndrome. Journal of cellular physiology. 2021;236(2): 824-38.

9. Kaya C, Pabuccu R, Berker B, Satiroglu H. Plasma interleukin-18 levels are increased in the polycystic ovary syndrome: relationship of carotid intimamedia wall thickness and cardiovascular risk factors. Fertility and sterility. 2010;93(4):1200-7.

10. Glintborg D, Andersen M, Richelsen B, Bruun J. Plasma monocyte chemoattractant protein-1 (MCP-1) and macrophage inflammatory proteinlalpha are increased in patients with polycystic ovary syndrome (PCOS) and associated with adiposity, but unaffected by pioglitazone treatment. Clinical endocrinology. 2009;71(5):652-8.

11. Atabekoglu C, Sönmezer M, Özmen B, Yarcı A, Akbıyık F, Taş̧̧ı T, et al. Increased monocyte chemoattractant protein-1 levels indicating early vascular damage in lean young PCOS patients. Fertility and Sterility. 2011;95(1):295-7.

12. Xiao N, He K, Gong F, Xie Q, Peng J, Su X, et al. Altered subsets and activities of B lymphocytes in polycystic ovary syndrome. Journal of Allergy and Clinical Immunology. 2019;143(5):1943-5.

13. Garlanda C, Hirsch E, Bozza S, Salustri A, De Acetis M, Nota R, et al. Nonredundant role of the long pentraxin PTX3 in anti-fungal innate immune response. Nature. 2002;420(6912):182-6.

14. Camaioni A, Klinger FG, Campagnolo L, Salustri A. The Influence of Pentraxin 3 on the Ovarian Function and Its Impact on Fertility. Frontiers in Immunology. 2018;9:2808.

15. Varani S, Elvin JA, Yan C, DeMayo J, DeMayo FJ, Horton HF, et al. Knockout of pentraxin 3, a downstream target of growth differentiation factor-9, causes female subfertility. Molecular endocrinology. 2002;16(6):1154-67.

16. MK S, B C, EY K, JE P, ES H, HJ L, et al. Elevated Pentraxin 3 in Obese Adipose Tissue Promotes Adipogenic Differentiation by Activating Neuropeptide Y Signaling. 2018;9:1790.

17. Brunetta E, Folci M, Bottazzi B, De Santis M, Gritti G, Protti A, et al. Macrophage expression and prognostic significance of the long pentraxin PTX3 in COVID-19. Nature immunology. 2020;22(2021):19-24.

18. Pan J, Zhou C, Zhou Z, Yang Z, Dai T, Huang H, et al. Elevated ovarian pentraxin 3 in polycystic ovary syndrome. Journal of assisted reproduction and genetics. 2021:1-7.

19. Salustri A, Garlanda C, Hirsch E, De Acetis M, Maccagno A, Bottazzi B, et al. PTX3 plays a key role in the organization of the cumulus oophorus extracellular matrix and in in vivo fertilization. Development. 2004;131(7): 1577-86.

20. McKenzie LJ, Pangas SA, Carson SA, Kovanci E, Cisneros P, Buster JE, et al. Human cumulus granulosa cell gene expression: a predictor of fertilization and embryo selection in women undergoing IVF. Human reproduction (Oxford, England). 2004;19(12):2869-74.

21. Zhuo L, Yoneda M, Zhao M, Yingsung W, Yoshida N, Kitagawa Y, et al. Defect in SHAP-hyaluronan complex causes severe female infertility. A study by inactivation of the bikunin gene in mice. The Journal of biological chemistry. 2001;276(11):7693-6.

22. Wyskida K, Franik G, Choręza P, Pohl N, Markuszewski L, Owczarek A, et al. Pentraxin 3 Levels in Young Women with and without Polycystic Ovary Syndrome (PCOS) in relation to the Nutritional Status and Systemic Inflammation. Int J Endocrinol. 2020;2020:1380176.

23. Aydogdu A, Tasci I, Tapan S, Basaran Y, Aydogan U, Meric C, et al. High plasma level of long Pentraxin 3 is associated with insulin resistance in women with polycystic ovary syndrome. Gynecological Endocrinology. 2012;28(9):722-5.

24. Tosi F, Di Sarra D, Bonin C, Zambotti F, Dall'Alda M, Fiers T, et al. Plasma levels of pentraxin-3, an inflammatory protein involved in fertility, are reduced in women with polycystic ovary syndrome. European journal of endocrinology. 2014;170(3):401-9.

25. Sahin FK, Sahin SB, Balik G, Ural UM, Tekin YB, Cure MC, et al. Does low pentraxin-3 levels associate with polycystic ovary syndrome and obesity? Int J Clin Exp Med. 2014;7(10):3512.

26. Wyskida K, Franik G, Pohl N, Markuszewski L, Owczarek A, Madej P, et al. Pentraxin 3 as a marker of endothelial dysfunction in young women with polycystic ovary syndrome (PCOS). Scandinavian journal of clinical laboratory investigation. 2019;79(6):419-23.

27. consultation* We. Appropriate body-mass index for Asian populations and its implications for policy and intervention strategies. Lancet. 2004; 363(9403):157-63.

28. Ristagno G, Fumagalli F, Bottazzi B, Mantovani A, Olivari D, Novelli D, et al. Pentraxin 3 in Cardiovascular Disease. Frontiers in immunology. 2019;10:823.
29. Netti G, Lucarelli G, Spadaccino F, Castellano G, Gigante M, Divella C, et al. PTX3 modulates the immunoflogosis in tumor microenvironment and is a prognostic factor for patients with clear cell renal cell carcinoma. Aging (Albany NY). 2020;12(8):7585-602.

30. Dubin R, Li Y, IX J, Shlipak M, Whooley M, Peralta C. Associations of pentraxin-3 with cardiovascular events, incident heart failure, and mortality among persons with coronary heart disease: data from the Heart and Soul Study. American heart journal. 2012;163(2):274-9.

31. Rudnicka E, Kunicki M, Suchta K, Machura P, Grymowicz M, Smolarczyk R. Inflammatory Markers in Women with Polycystic Ovary Syndrome. Biomed Res Int. 2020;2020:4092470.

32. Güdücü N, Görmüş U, Alp E, Kavak ZN, Dünder İ. Reciprocal action of pentraxin-3 and Crp in women with polycystic ovary syndrome. European Journal of Inflammation. 2014;12(1):161-6.

33. Korhonen K, Unkila-Kallio L, Alfthan $\mathrm{H}$, Hämäläinen E, Tiitinen A, Mikkola T, et al. Plasma pentraxin 3 is higher in early ovarian hyperstimulation syndrome than in uncomplicated in vitro fertilization cycle of high-risk women. Archives of gynecology and obstetrics. 2020;301(6):1569-78.

34. Wang F, Pan J, Liu Y, Meng Q, Lv P, Qu F, et al. Alternative splicing of the androgen receptor in polycystic ovary syndrome. Proceedings of the National Academy of Sciences. 2015;112(15):4743-8.

35. Trigunaite A, Dimo J, Jørgensen T. Suppressive effects of androgens on the immune system. Cellular immunology. 2015;294(2):87-94.

36. Klein $\mathrm{SL}$, Flanagan KL. Sex differences in immune responses. Nature Reviews Immunology. 2016;16(10):626-38.

37. Wang $D$, Weng $Y$, Zhang $Y$, Wang $R$, Wang $T$, Zhou J, et al. Exposure to hyperandrogen drives ovarian dysfunction and fibrosis by activating the NLRP3 inflammasome in mice. The Science of the total environment. 2020; 745:141049.

38. Ashcroft GS, Mills SJ. Androgen receptor-mediated inhibition of cutaneous wound healing. The Journal of clinical investigation. 2002;110(5):615-24.

39. González F, Sia CL, Bearson DM, Blair HE. Hyperandrogenism induces a proinflammatory TNFa response to glucose ingestion in a receptordependent fashion. The Journal of Clinical Endocrinology and Metabolism. 2014;99(5):E848-E54

\section{Publisher's Note}

Springer Nature remains neutral with regard to jurisdictional claims in published maps and institutional affiliations.

Ready to submit your research? Choose BMC and benefit from:

- fast, convenient online submission

- thorough peer review by experienced researchers in your field

- rapid publication on acceptance

- support for research data, including large and complex data types

- gold Open Access which fosters wider collaboration and increased citations

- maximum visibility for your research: over $100 \mathrm{M}$ website views per year

At BMC, research is always in progress.

Learn more biomedcentral.com/submissions 